Postprint version $\quad: \quad 1.0$

Journal website $\quad:$ https://www.journals.elsevier.com/nurse-education-in-practice

Pubmed link

DOI

: https://www.ncbi.nlm.nih.gov/pubmed/31352089

: doi: 10.1016/j.nepr.2019.07.005

This is a Nivel certified Post Print, more info at nivel.nl

\title{
Late dropout from nursing education: An interview study of nursing students' experiences and reasons
}

\author{
Ellen J.M. Bakker ${ }^{a, b,{ }^{*} 1}$, Kim J. Verhaegh ${ }^{c}$, Jos H.A.M. Kox ${ }^{a, d}$, Allard J. van der \\ Beek $^{b}$, Cécile R.L. Boot ${ }^{b}$, Pepijn D.D.M. Roelofs ${ }^{a, f}$, Anneke L. Francke ${ }^{b, e}$
}

a Rotterdam University of Applied Sciences, Research Centre Innovations in Care, P.O. Box 25035, 3001, HA Rotterdam, the Netherlands

b Amsterdam UMC, Vrije Universiteit Amsterdam, Department of Public and Occupational Health, Amsterdam Public Health Research Institute, Van der Boechorststraat 7, 1081, BT Amsterdam, the Netherlands

c Amsterdam UMC, AMC, Department of Internal Medicine, Section of Geriatric Medicine, P.O. Box 22660, 1100, DD Amsterdam, the Netherlands

d Erasmus University Medical Centre, Department of General Practice, P.O. Box 2040, 3000, CA Rotterdam, the Netherlands

e NIVEL Netherlands Institute for Health Services Research, P.O. Box 1568, 3500, BN Utrecht, the Netherlands

f Department of Health Sciences, Community and Occupational Medicine, University Medical Center Groningen, University of Groningen, Groningen, The Netherlands

\begin{abstract}
The global shortages of nurses require a closer look at why nursing students stop in the later years of their degree programme. The purpose of this study is to explore nursing students' experiences and reasons that lead to this late dropout. Semi-structured interviews were held in 2017 with eleven former nursing students who dropped out in the third year of their Bachelor's Nursing degree programme in the Netherlands. Data was collected and analysed iteratively, following the principles of Thematic Analysis. Two core themes were identified: 'ending up in a downward spiral of physical, psychological and social problems' and 'experiencing an increasing mismatch between expectations and reality'. Reasons for late dropout from nursing education are diverse and interlinked. In contrast with studies on early dropout, academic difficulties did not play a major role in late dropout. Negative experiences during clinical placements led to
\end{abstract}

\footnotetext{
*Corresponding author. Rotterdam University of Applied Sciences, Research Centre Innovations in Care, P.O. Box 25035, 3001, HA Rotterdam, the Netherlands. E-mail addresses: e.j.m.bakker@hr.nl (E.J.M. Bakker), k.j.verhaegh@amsterdamumc.nl (K.J.Verhaegh), j.h.a.m.kox@hr.nl (J.H.A.M. Kox), a.vanderbeek@vumc.nl (A.J. van der Beek), CRL.Boot@vumc.nl (C.R.L. Boot), p.roelofs@umcg.nl (P.D.D.M. Roelofs), A.Francke@nivel.nl (A.L. Francke).
} 
Bakker, E.J.M., Verhaegh, K.J., Kox, J.H.A.M., Beek, A.J. van der, Boot, C.R.L, Roelofs, P.D.D.M., Francke, A.L. Late dropout from nursing education: An interview study of nursing students' experiences and reasons. Nurse Education in Practice: 39 (2019) 17-25

dropout in both groups. One group lacked a safe learning environment in clinical placements, study coaching and psychological support. The other group missed realistic information provision about nursing education and the broad range of career opportunities in nursing.

\section{Introduction}

There is a growing shortage of healthcare professionals worldwide (e.g. Global Health Workforce Alliance, 2013; Wismar et al., 2018). For instance, in the USA, shortages of about 154,000 registered nurses (RNs) are expected by 2020 and of about 510,000 RNs by 2030 (Zhang et al., 2017). In the Netherlands too, there are significant shortages of nursing staff, particularly nurses with a Bachelor's qualification. Forecasts give about 4900 unfulfilled vacancies for nurses with a Bachelor's degree in nursing by 2020 (Joldersma et al., 2016).

The nursing profession therefore offers good job prospects in principle. Many young people initially feel attracted to the nursing profession and there is a substantial inflow of students in nursing programmes. However, dropout - in the sense of leaving the nursing degree programme before graduation - is a recognized problem in nursing education (Eick et al., 2012). The estimated percentages of nursing students leaving their programme before graduation varies between countries, e.g. 9\% in Finland (Kukkonen et al., 2016), at least 20\% in the UK (Willis, 2015) and between 10 and 42\% in Australia (Gaynor et al., 2007). Cumulative dropout rates also vary according to the programme year. In the Netherlands, dropout before the second year of the programme (early dropout) fluctuated between $13.6 \%$ and $18.5 \%$ in the period $2009-2014$, and dropout after three years of studying (late dropout) between $17.7 \%$ and $24.3 \%$. Cumulative late dropout was on average $6 \%$ higher than early dropout (Vereniging Hogescholen, 2018).

Dropout from nursing education represents a loss of human capital as well as financial capital and is particularly problematic considering the severe shortage of nursing staff. Late dropout is most problematic: the student has studied for several years without a clear result, but has invested time, energy and study funding. Furthermore, they have already laid claim to a relatively large number of clinical training places. In the context of rising shortages of nursing staff and the limited number of clinical placements and clinical training places (Buchan and Seccombe, 2011; Smith et al., 2015; Young et al., 2014), it is especially important that students do not stop their nursing training in the later years.

However, previous studies mainly included dropping out of nursing education in the first- and/or second-year of nursing education (e.g. Andrew et al., 2008; Griswold, 2014; Harvey and McMurray, 1994; Harvey and McMurray, 1997; O'Donnell, 2011; Rankin, 2009), or mixed samples without performing separate analyses to differentiate between dropping out early or late (Dante et al., 2011; Glogowska et al., 2007; Glossop, 2002; Hamshire et al., 2012; Kukkonen et al., 2016; Wilson and Levy, 1978). These studies often concern quantitative survey research or qualitative interview studies, and show that the risk of nursing students dropping out is often partially related to demographic factors. For instance, factors such as being relatively young on entry (Mulholland et al., 2008; Pryjmachuk et al., 2009) and being male (McLaughlin et al., 2010; Mulholland et al., 2008; Pryjmachuk et al., 2009) are associated with a higher risk of dropout. Academic and cognitive factors play a role in early dropout: poor secondary school performance (Pryjmachuk et al., 2009), being unprepared for university (Andrew et al., 2008), academic difficulties (Glossop, 2002), and low academic self-efficacy (Harvey and McMurray, 1994) have been associated with dropout.

Furthermore, associations between dropping out and personality traits and health factors have been described in previous research, e.g. poor ability to cope with stress (Deary et al., 2003), low emotional intelligence (Rankin, 2009), low score on two of five personality traits (agreeableness and conscientiousness) (Deary et al., 2003), high psychoticism scores (McLaughlin et al., 2008) and health problems (Glogowska et al., 2007; Glossop, 2002). 
Bakker, E.J.M., Verhaegh, K.J., Kox, J.H.A.M., Beek, A.J. van der, Boot, C.R.L, Roelofs, P.D.D.M., Francke, A.L. Late dropout from nursing education: An interview study of nursing students' experiences and reasons. Nurse Education in Practice: 39 (2019) 17-25

In addition, associations have been described with professional and educational characteristics: e.g. a feeling of having made a wrong choice (Glossop, 2002), and unmet or unrealistic expectations (O'Donnell, 2011), theory-practice gap (Ten Hoeve et al., 2017), lack of faculty support (Griswold, 2014), and unpleasant experiences and lack of support during clinical placements (Eick et al., 2012). Finally, social or economic factors, such as problems in the family and financial difficulties, have been associated with dropout (Glossop, 2002; Last and Fulbrook, 2003).

None of the abovementioned studies focused exclusively on late dropout. They mainly included formal first- and/or second-year nursing students (e.g. Andrew et al., 2008; Griswold, 2014; Harvey and McMurray, 1994; Harvey and McMurray, 1997; O'Donnell, 2011; Rankin, 2009), or mixed samples of early and late dropped out students, without performing separate analyses differentiating between these subgroups (Dante et al., 2011; Glogowska et al., 2007; Glossop, 2002; Hamshire et al., 2012; Kukkonen et al., 2016; Wilson and Levy, 1978). In contrast, recently a relevant study was performed in the Netherlands following a group of 17 third-year Bachelor of Nursing students (Ten Hoeve et al., 2017). That study concluded that support from lecturers and mentors as well as working in a pleasant team were important factors in ensuring students completed the programme. However, ten Hoeve et al.'s sample consisted of 15 students who continued with the programme and only two who dropped out. Therefore, the objective of the study presented in this paper was to give additional insight into students' experiences that contribute to late dropout in Bachelor of Nursing degree programmes in the Netherlands. Since the Dutch fouryear programme might differ from other countries, context information is provided in Fig. 1 and Appendix A. This qualitative study is part of a larger Dutch research project named SPRiNG, an acronym for Studying Professional Resilience in Nursing students and new Graduates (Bakker et al., 2018). Findings will be used to design tailored interventions for the prevention of late dropout in the Netherlands.

\section{Methods}

\subsection{Design}

An exploratory qualitative study design was applied, using in-depth face-to-face interviews.

\subsection{Sample and recruitment}

A convenience sample of former students, based on their accessibility, was recruited from Bachelor of Nursing degree programmes at two Dutch universities of applied sciences. One university was situated in Rotterdam, the second largest city, in the west of the Netherlands. The other university was in a smaller city, namely Nijmegen, the tenth largest city in the Netherlands, situated in the south-eastern part of the country. Part of the interviewed participants $(n=8)$ were recruited through current nursing students who participated in the cohort study of the broader SPRiNG research project (Bakker et al., 2018). These students were asked to act as an intermediary to contact and recruit former nursing students from their network. Another part of the interviewees $(n=3)$ were recruited through invitation letters sent by the student administration desks to former nursing students. Only those who gave permission to be contacted by the researcher were approached by the main investigator (EB), using e-mail or telephone.

Two other Dutch universities of applied sciences, in Amsterdam and The Hague, were initially willing to recruit former students for us, but none of the former students approached by the administration desks responded positively to the request.

Only nursing students who voluntary quit the programme in the third or fourth year were eligible for inclusion. All participating former students $(n=11)$ except one were female. Their ages ranged between 21 and 34 at the time of interviewing. All except one started their nursing training at a relatively young age (i.e. between 17 and 20) and had no previous work experience in nursing. Most 
Bakker, E.J.M., Verhaegh, K.J., Kox, J.H.A.M., Beek, A.J. van der, Boot, C.R.L, Roelofs, P.D.D.M., Francke, A.L. Late dropout from nursing education: An interview study of nursing students' experiences and reasons. Nurse Education in Practice: 39 (2019) 17-25

of them lived in their own student house or room. None of them had children to look after. All except three came straight from secondary school. None of the students belonged to an ethnic minority and all had left nursing education during or at the end of their third year in the degree programme (see Appendix $B$ for the characteristics of the study population).

\section{Data collection}

All interviews were performed by the first author (EB), a female registered nurse, medical anthropologist trained in qualitative research, nurse lecturer and PhD candidate in the 'SPRiNG study', which this interview study is part of. Her professional background enabled her to build up good rapport with the respondents. She did not know the participants beforehand, except for one student who had been following one of her classes (16 hrs in total).

Ten face-to-face interviews were conducted, and one interview using Skype. We used an interview guide with open questions (see Appendix C). The themes and topics of the interview guide were derived from relevant literature (e.g. Dante et al., 2011; Glogowska et al., 2007; Glossop, 2002; Hamshire et al., 2012; Kukkonen et al., 2016; Ten Hoeve et al., 2017), and formulated in discussions with all co-authors. All the in-depth interviews took place at a location according to the preferences of the interviewees, mostly a quiet location at the university. One interview took place in the communal room of a student house, another interview took place in a public location, and one was a Skype interview with an interviewee who had moved to Australia. The duration of the interviews varied between 47 and $78 \mathrm{~min}$, with an average of $59 \mathrm{~min}$.

Observations and impressions were written down by the interviewer immediately after the interview to enable proper recall of the interviews and to support the analysis of the data. All interviews were audio-recorded and transcribed verbatim. Member checking was applied: all interviewees received the transcribed interview and checked it for inaccuracies. No alterations were made.

The eleventh interview did not provide any new insights, which might be an indication of data saturation. However, to maximize variation in relevant background characteristics we tried to recruit male interviewees, of older age and with a non-Caucasian background. Eventually, we were unable to include participants of these groups, so recruitment was ended.

\section{[Figure 1.]}

\section{Data analysis}

Data collection and analysis were done in an iterative process, following the six steps of Thematic Analysis (Braun and Clarke, 2006): 1) Becoming familiar with the data; 2) Creating codes; 3) Find common themes; 4) Review of themes; 5) Defining and naming definitive themes; 6) Reporting.

The first author (EB) analysed all interviews, while eight interviews were also independently analysed by other co-authors with various professional backgrounds, such as nursing, physiotherapy, and public and occupational health research. They all have expertise in qualitative research. The main steps in the analyses were as follows. The first two authors (EB, KV) read and reread the initial four interviews several times to become familiar with the data. Secondly, they (EB, KV) inductively coded interview fragments and made a short analytic summary of each of these interviews. They discussed these summaries and the main codes given to interview fragments with the supervising coauthor (AF), who co-analysed three interviews. Subsequently, the first author (EB) continued with the analyses of later interviews by assigning codes to interview fragments. During this stage in the analysis process, the first author (EB) sorted the main codes into categories, displayed as mind maps. The mind maps and coding were checked by returning to the interview transcripts, and were discussed in the broader team, which also included the other co-authors ( $\mathrm{AvdB}, \mathrm{CB}, \mathrm{PR}, \mathrm{JK}$ ). $A$ 
Bakker, E.J.M., Verhaegh, K.J., Kox, J.H.A.M., Beek, A.J. van der, Boot, C.R.L, Roelofs, P.D.D.M., Francke, A.L. Late dropout from nursing education: An interview study of nursing students' experiences and reasons. Nurse Education in Practice: 39 (2019) 17-25

narrative approach was used to evoke the very nature of the subjective experiences and reasons of the former students for their dropout of nursing education.

\subsection{Ethical considerations}

Before participation in this interview study, all potential participants received written information about the study aim, and the protection of their privacy. In addition, the letter provided information about the voluntary character: participants could withdraw from the interview study at any time without further explanation. All participants signed informed consent forms before the interviews were conducted. The study complied with the Netherlands Code of Conduct for Scientific Practice from the Association of Universities in the Netherlands (2012), and was exempted from formal medical ethical review in accordance with the Dutch Medical Research Involving Human Subjects Act (see https://english.ccmo.nl/).

\section{Findings}

Two core themes were revealed by the analyses, namely 'ending up in a downward spiral' and 'increasingly experiencing a mismatch between expectations and reality'. These two main themes are related to the two groups of former nursing students that we identified: one group that found the programme - especially the clinical placements - very hard in combination with many other problems, and another group that eventually concluded that the training and professional prospects did not suit them. These findings will be explained in more detail as a narrative in the following sections.

In the Dutch Bachelor Nursing degree programme, successive 18- to 20-week clinical placements take place in the second, third, and fourth year of the programme. During clinical placements, nursing students practise nursing roles in various healthcare settings under the guidance of a clinical supervisor (a Registered Nurse) and a faculty member from the Nursing degree programme. This faculty member monitors the quality of the learning climate and student progress, and is responsible for the final assessment and grading.

\subsection{Ending up in a downward spiral}

Increasing problems with the toughness of the degree programme and clinical placements.

The former students who were interviewed were positive on balance about their first academic year and had generally passed their end-of year exams at the first attempt. The second year also generally went reasonably well. But in the third year they faced tougher requirements, in both the theoretical part and the clinical placements. Although a few still encountered academic difficulties, this was not commonly mentioned as one of the main reasons for quitting. Some became exhausted from the combination of studying hard for the theoretical part of the programme and the demanding clinical placements. "... The results were good, but I had to work really hard for that ... I had to work hard to keep myself together during the clinical placement ... I was simply shattered, I was incredibly tired" (interviewee 1). If the pressure got too much, some of them made even more effort to do their best rather than taking things down a notch.

These students experienced the clinical placements to be more burdensome than the theoretical learning in-class and online. Lack of time for patients was mentioned by one interviewee as a major stressor: "I stood there with one colleague while someone was lying there dying ... my colleague came back with tears in her eyes, she said, 'Well, that man who's lying there dying, he said he was feeling so alone. And all we're doing is running around.' So horrible..." (interviewee 6).

\subsubsection{Losing their grip on the learning process}

As the degree programme progressed, the former students increasingly felt unable to get a grip on the learning process. The lack of proper supervisory support and continuity in supervision during 
Bakker, E.J.M., Verhaegh, K.J., Kox, J.H.A.M., Beek, A.J. van der, Boot, C.R.L, Roelofs, P.D.D.M., Francke, A.L. Late dropout from nursing education: An interview study of nursing students' experiences and reasons. Nurse Education in Practice: 39 (2019) 17-25

the clinical placement contributed to this problem. Sometimes there was a lack of clinical supervision at Bachelor level, for instance in nursing homes where most staff were certified nursing assistants and the supervision was provided remotely. "But whenever I arrived on the ward, it was all really a case of right, how am I actually going to tackle this?" (interviewee 7). In one case there was no clinical supervisor at all due to staffing shortages. The lack of a role model and concrete supervision in the workplace led to delays in the learning process and eventually to failing the clinical placement.

One student with dyslexia received mainly distance supervision: she hardly worked together with her clinical supervisor from the hospital setting in practice: "... often there is contact via e-mail like forwarding assignments ... that is all it takes, and then they just have to assess whether you have demonstrated your competence ... And you have to prove that mainly through reporting." (interviewee 2).

In other cases, there was supervision, but the student did not 'click' with the clinical supervisor, they felt positive feedback was lacking or they felt they were mainly being judged. "... then she stood there ... quite literally looking over my shoulder and monitoring everything. And she said: ' ... make sure you read those names properly'. But at that stage I couldn't read so well because I was thinking constantly: 'Oh, I can't fail.' Well, I just felt incredibly stressed when I was around her. So, I simply couldn't properly remember what I'd read. And that's partly where it went wrong, because then she'd start asking things: 'Did you pay attention to this and that. And how will you be tackling this and this', and so on. Well, then I froze and couldn't speak anymore..." (interviewee 9).

\subsubsection{Lack of support from the programme organization}

Some people tried to obtain help from their study career coach, a faculty member, but did not receive the expected support. "Well, this study career coach had a lot of problems at home and he started comparing my situation with that of his [family member] and, well, that didn't really help, so ... my feeling is I would simply have done better sorting it out myself, right, rather than going to him with it" (interviewee 2). "... having a chat with him is formally required, but I never had the feeling that I was getting anything from this..." (interviewee 1). Faculty members, who were involved in the clinical placement did not always provide the back-up support students wanted. In one case the faculty member did not act upon problems related to the learning environment: "I did send her an email once saying, 'Hey, I still haven't got a clinical supervisor.' But well, I never got anything back, so then I thought, OK that's apparently how things are" (interviewee 6). Sometimes they did not feel supported by the faculty member during their clinical placement: "... the faculty member very much relied on what the clinical supervisor said ... and not so much on what I said. So that also made me feel powerless." (interviewee 2). Some interviewees mentioned the lack of peer support during group sessions at school. One interviewee felt he was the only person who had unsatisfactory clinical placements: "... that is especially difficult when people pass their clinical placements with high grades and you have to admit you didn't pass." (interviewee 7). Another interviewee felt it was not safe to talk about feelings and doubts in the classroom. "...So, one person was like: 'I'm better because I did clinical placements there and there and I'm working there and there.' But right, that competitive atmosphere in class does make you feel less like ... less like talking to an entire group, let's say..." (interviewee 11). But despite the lack of peer support in group sessions, most students found peer support in individual contact with fellow students. The lack of support from the degree programme

organization meant that respondents were more likely to discuss programme or clinical placement problems with their family, their partner and/or friends or fellow students than with relevant professionals within the organization.

\subsubsection{Character traits that impede the learning process}

The former students who were interviewed also made a link between character traits and the stagnating learning process and their ultimate decision to leave the programme. The traits they mentioned were being too insecure, too perfectionist, over-sensitive, reserved or depressed, tending 
Bakker, E.J.M., Verhaegh, K.J., Kox, J.H.A.M., Beek, A.J. van der, Boot, C.R.L, Roelofs, P.D.D.M., Francke, A.L. Late dropout from nursing education: An interview study of nursing students' experiences and reasons. Nurse Education in Practice: 39 (2019) 17-25

to worry too much, or lacking the necessary flexibility or ability to talk about problems. "...I didn't manage to write the reflection reports either because I had too many doubts about them, I never found them good enough anyway, so then I simply didn't hand them in. Sometimes I did, but then I'd think, well, they aren't good enough..." (interviewee 10). Other mentioned difficulties were: standing up for yourself properly, setting limits, reflecting on situations, or dealing with the constant changes in patient care. They also sometimes felt too young or not ready to become a professional nurse dealing with dramatic events: “... The biggest thing was that I kind of felt I'm simply not yet ready to be a nurse because I took everything too personally and was just so sensitive to things and I couldn't deal with it..." (interviewee 1).

\subsubsection{Increase in physical, psychological and social problems}

Doubts and uncertainty about their own performance and a feeling that they could not get a grip on the learning process during the clinical placement increasingly led to worrying, insomnia and dreading the next day at the clinical placement. The interviewees described this as an insidious process that they only became aware of after some time.

Some also struggled with depressive feelings. A fail grade for a clinical placement, for example, could trigger a depression: "I didn't notice it myself at first, but as I said, there came a point when people around me said, 'You know, this really isn't going well'. But right, it was only when it became clear that well [I would get a fail grade for my clinical placement], that everything collapsed. Then I collapsed too ... all I could do was cry ... But this is something that apparently in my case ... just occurred to be really triggered by what happened (interviewee 6).

For most of the former students, the stress and pressure led to less care for themselves. The interviewees mentioned drinking red wine more often, poor diet, smoking a great deal, stopping sports, and giving up relaxing and enjoyable activities, hobbies and social contacts. They also spoke of "forgetting yourself" and "losing yourself". "I spent three whole weeks thinking about this an awful lot. I actually wrote down clearly for myself the reason why I simply couldn't keep it up. And won't be able to keep it up once I've graduated. And right, you know, I love giving care to people, but I lose myself in that" (interviewee 3).

These people became increasingly exhausted, took less and less care of themselves, postponed their study assignments more and more often, dreaded their clinical placements, became demotivated and eventually decided to throw in the towel. "Because then things really started getting worse and worse mentally. In the end, that's also the reason why I stopped. I simply couldn't cope anymore. It was simply so painful and difficult for me getting up every day and having to go to my clinical placement. And as a result, I couldn't function properly in my clinical placement" (interviewee 10). "... But what I discovered in the third year was that I was really not ready for this; I just realized that I was too young in the sense that I took it all too much to heart ... My final year was in psychiatry ... All the stuff that happened there just made me feel really sad..." (interviewee 1).

Being permanently tired, not enjoying the clinical placement and not feeling in control of the learning process made them doubt whether they were suited to the profession. This also intensified the downward spiral they had ended up in, and that eventually led to their decision to stop.

\subsubsection{Conclusion: I can't keep this up}

During the third academic year, the students in question became increasingly aware of the downward spiral in which they had ended up. Most of them became more and more exhausted, two were clinically diagnosed with a depression. They put an early stop to their clinical placements, reported sick or took a time-out upon the advice of their study career coach. Some went to see their general practitioner and were referred to a psychologist. This period was used to recover, both physically and mentally, and to take stock of things. For most, a dread of the next clinical placement and a lack of confidence in the ability to get a pass grade for the next clinical placement played a major role in the final decision to stop. Curriculum reforms that led to the cancellation of credits 
Bakker, E.J.M., Verhaegh, K.J., Kox, J.H.A.M., Beek, A.J. van der, Boot, C.R.L, Roelofs, P.D.D.M., Francke, A.L. Late dropout from nursing education: An interview study of nursing students' experiences and reasons. Nurse Education in Practice: 39 (2019) 17-25

could also be the final straw. A striking feature was that all the respondents mainly sought support in this process outside the programme organization: from their parents, other family members, partner, friends or professional bodies.

\subsection{Increasingly experiencing a mismatch between expectations and reality}

\subsubsection{Degree programme different to what they expected}

There was another group of nursing students who withdrew in a late stage of their programme for whom psychological, physical and social problems did not play a big role. Nor did they find the programme tough generally in terms of the cognitive or theoretical aspects. At first, they seemed to progress through the programme quite effortlessly. But the first clinical placements were disappointing because they differed from their expectations. Some interviewees were disappointed by the content of the degree programme and the prospects that were presented. For example, one student noticed during clinical placements that she was more interested in the medical and technical side of nursing. "I soon realized that the questions I asked focused on the medical treatment ... and that I often got the answer that this is something the doctor knows ... that's not our job ... Later on in the programme, that became one of the reasons for me to stop." (interviewee 4). In the nursing programme, she did hear something about the advanced nursing practice role, in which medical and nursing tasks are combined, but there was no clear information about this career prospect

\subsubsection{Increasing doubts about the profession}

Various former students explained that they had originally a different impression of nursing as a profession. They gradually discovered that the profession did not fit with what they wanted in their lives and work, for example because it involved many non-complex caring tasks, they had to work according to illness-focused protocols and little attention was paid to the individual needs of the patients themselves. "... It wasn't really ... focused on the patient ... It was really, well, focused on the clinical picture and getting them back home as quickly as possible, you know..." (interviewee 8).

One reason why they only discovered this in the third year is that they were always expecting that the ideal clinical placement was still to come. "Of course, I'd focused blindly on that hospital ... Every time I just thought, this just isn't for me but the next one will be the right one..." (interviewee 5). "Well, I did go through it pretty easily. I didn't enjoy it that much, but I thought right, that hospital, it will turn up eventually. And you just have to have this as a basis..." (interviewee 8). But then that idealized clinical placement turned out to be disappointing too. "Right, I really thought, then you do all kinds of exciting things and so on, right, of course you do that too in a hospital. You certainly get that as well, but I'd developed a kind of aversion to all that morning care and all that washing and cleaning people ... I kind of thought: do I have to do that every day? ... I'd got it into my head that you don't have to do that anymore if you work in a hospital" (interviewee 5). Some interviewees could not cope with the irregular shifts either. "And it made me a bit, well, disorientated. In my behaviour too, becoming a bit moody. And that was also quite a major thing that made me think right, if you don't even feel good on that ward, or don't feel good in the hospital ... And also, those irregular hours ... which you also get ... Well, how does that affect you?" (interviewee 8).

Finally, the nurse's subordinate position with respect to the doctor was also mentioned. "I mean, I'm not a doctor so I understand that I can't make the decisions. But I do feel you really notice that you are ranked below them." (interviewee 5).

What the participants cited above had in common were their doubts about whether this was the kind of work they wanted to do as their future career. They were aware of this feeling in their contacts with fellow nurses. "When I looked at them, at what they did. And then I basically thought, well, this isn't what I really want for my life, let's say" (interviewee 5). 
Bakker, E.J.M., Verhaegh, K.J., Kox, J.H.A.M., Beek, A.J. van der, Boot, C.R.L, Roelofs, P.D.D.M., Francke, A.L. Late dropout from nursing education: An interview study of nursing students' experiences and reasons. Nurse Education in Practice: 39 (2019) 17-25

\subsubsection{Taking stock: this isn't what I want}

During the third year, the interviewees in question gradually lost faith that the programme would ever be able to satisfy their expectations. They became increasingly aware that the degree programme and the future professional prospects did not match their wishes and expectations, and they eventually concluded: "This is not what I want in my life". They took stock and decided to stop. The difference with the previous group is that this decision was not made in a situation involving increasingly serious problems; it was far more a conscious choice and an awareness that nursing work and the associated training programme did not fit with what they wanted in their professional lives.

\section{Discussion}

Two core themes were revealed by the analyses of the interviews with the formal nursing students in this study: ending up in a downward spiral of increasing physical, mental and social problems; and becoming increasingly aware of a mismatch between expectations and reality.

Late dropout from nursing education, particularly in the group of students who ended up in a downward spiral, involved a variety of different experiences and reasons: increasing problems with the toughness of the degree programme and clinical placements, losing grip of the learning process due to a lack of coaching and support, character traits leading to increasing physical, psychological and social problems, and the ultimate decision to quit the degree programme.

Dropout has also been described as a multifactorial phenomenon in previous studies among nursing students who dropped out in their first or second year of study and mixed groups of formal nursing students (e.g. Andrew et al., 2008; Eick et al., 2012; Glogowska et al., 2007; O'Donnell, 2011). For instance, Andrew et al. (2008) interviewed Australian formal nursing students who were already suffering from various physical, mental and social problems in their first year that are comparable to the problems experienced by our group of students who ended up in a downward spiral in their third year of study. The mismatch between expectations and reality has also been described as unmet or unrealistic expectations in studies of early dropout (Harvey and McMurray, 1997; O'Donnell, 2011).

However, other factors in studies of early dropout differed from those described in our study and the study by Ten Hoeve et al. (2017) on late dropout. In nursing students who withdraw in an early stage of the programme, being unprepared for university (Andrew et al., 2008), low academic selfefficacy (Harvey and McMurray, 1994) and academic difficulties (Glossop, 2002) often play a prominent role in the decision to stop. Such factors did not play a major role in the decision to stop in the later years of the nursing degree programme.

Some previous studies (e.g. Glossop, 2002; Kukkonen et al., 2016) also found that geographical circumstances, viz. a long distance between home and university or clinical placement, played a role in the decision to stop. We did not find indications for this in our study, which might be related to the fact that the Netherlands is a small country.

In addition, unlike in some previous studies (e.g. Andrew et al., 2008; Glossop, 2002; Hamshire et al., 2012), none of the former students stopped because of financial reasons. This might be related to the Dutch context where students can take out interest-free loans provided by the government to finance their studies. The effect was rather the reverse, in fact: the accumulated study debt had initially been a reason for some students to continue despite doubts.

A strength of this study is that we gained in-depth, detailed information about reasons specifically for late dropout. This adds to previous studies that mainly focused on early dropout or that did not differentiate between early and late dropout.

We reached data saturation after interviewing eleven female, non-migrant former nursing students. However, findings cannot automatically be generalized to the diverse population of Dutch former nursing students because of some limitations. We only included former students from two universities of applied sciences, despite attempts to recruit former students from other applied 
Bakker, E.J.M., Verhaegh, K.J., Kox, J.H.A.M., Beek, A.J. van der, Boot, C.R.L, Roelofs, P.D.D.M., Francke, A.L. Late dropout from nursing education: An interview study of nursing students' experiences and reasons. Nurse Education in Practice: 39 (2019) 17-25

universities. Another limitation is that - although we tried - we were not able to recruit more than one male interviewee, and one interviewee older than 23 years. In addition, we were not able to recruit former nursing students with a migrant background.

\section{Conclusions and recommendations}

Two groups can be distinguished among the nursing students who withdrew in a late stage of their programme. One group consisted of those who found the training and especially the clinical placements difficult, and who ended up in a downward spiral of increasing problems ultimately leading to them dropping out of nursing education. The second group consisted of those who increasingly realized that the training and the future profession did not match their expectations and wishes.

To prevent late dropout resulting from a downward spiral of increasing problems, we recommend creating a safe learning environment in clinical placements, offering proper study coaching and making psychological support available.

To prevent the late dropout of students who experience a mismatch between expectations and reality, we recommend creating more realistic expectations by providing proper information. Realistic information should be provided about the degree programme and nursing practice before the start and during the earliest information and introduction days. To keep nursing students motivated in their third year, it is recommended that specific attention should be paid to the broad range of career opportunities and specialties within the nursing profession.

It is recommended that such measures are accompanied by further research. For instance, future research is needed to develop and evaluate intervention programmes that contribute to a safe learning environment with tailored support and coaching opportunities, to enable nursing students to direct their own learning and health. Moreover, in the context of rising shortages of nursing staff further research into late dropout is necessary and should include nursing students in all their diversity

\section{Conflicts of interest}

All authors declare that they have no competing interests.

\section{Funding}

This work was supported by the Netherlands Organization for Scientific Research (NWO) [grant number: 2014-01-31PRO], and the Rotterdam University of Applied Sciences.

\section{Ethical approval}

The study complied with the Netherlands Code of Conduct for Scientific Practice from the Association of Universities in the Netherlands (2012), and was exempted from formal medical ethical review in accordance with the Dutch Medical Research Involving Human Subjects Act (see https://english.ccmo.nl/).

\section{Acknowledgements}

The authors acknowledge the support of the nursing boards of Rotterdam University of Applied Sciences, HAN University of Applied Sciences, The Hague University of Applied Sciences and Amsterdam University of Applied Sciences for their support with the recruitment of participants. In this regard, special thanks are due to Remco Ebben, Marion van Harn, Christine Pijnappels, Lottie 
Bakker, E.J.M., Verhaegh, K.J., Kox, J.H.A.M., Beek, A.J. van der, Boot, C.R.L, Roelofs, P.D.D.M., Francke, A.L. Late dropout from nursing education: An interview study of nursing students' experiences and reasons. Nurse Education in Practice: 39 (2019) 17-25

Kuijt-Evers and Ria de Korte. Furthermore, special thanks are also offered to Clare Wilkinson and Hanny Groenewoud for their editorial support, and all participating former nursing students who were willing to contribute to this study.

Appendix A. Characteristics of the Bachelor of Nursing degree programme in the Netherlands

Setting: The Bachelor of Nursing programme in the Netherlands is offered by 17 universities of applied sciences.

Duration of the programme: Four years (equal to 240 ECTS according to the European Credit Transfer and Accumulation System; one ECTS represents $28 \mathrm{hrs}$ of students' work). A shorter programme is possible for students who already have a certificate of vocational nursing training.

Entrance requirements: A certificate of higher secondary education (in Dutch: HAVO or VWO) or secondary vocational training (in Dutch: $\mathrm{MBO}$ ).

Different educational trajectories: Full-time; part-time (for students with a secondary vocational nursing certificate who can combine the programme with paid work in a healthcare institution); combined work and study trajectories (possible from year 3); honours programme (for students who require an extra challenge through extra-curricular modules and/or opportunities to graduate in less time).

Nature and content of the programme: Students are trained for various healthcare settings, such as mental healthcare, community-based healthcare, hospital care, nursing home care and disabled care. The broad programme is based on the principles of competency-based learning and contains a combination of theoretical training $(1535 \mathrm{hrs})$, practical skills training and clinical training in various settings ( $2300 \mathrm{hrs}$ in total).

Main content of the full-time study programme per year, for the two included universities:

- Year 1: theoretical training and practical skills training, including a short introductory internship (between 1 and 10 weeks)

- Year 2: theoretical training and practical skills training, including one long or two short internships (18-20 weeks in total)

- Year 3: long internships (18-20 weeks), supported by theoretical training and minor subject or long internships (18-20 weeks)

- Year 4: minor subject or long internship (18-20 weeks), one long internship (18-20 weeks) and/or graduation assignment

Support structure: During their four years of study nursing students receive coaching regarding their study progress from a faculty member, mostly a master prepared RN, in the role of study career coach. In case of special needs students can apply for counselling on demand. During the internships, every student is supervised by a registered nurse, preferably with a Bachelor's degree, and is assigned to a faculty staff member who monitors the progress in the clinical training, the quality of the learning climate, and is responsible for the final assessment and grading. 
Bakker, E.J.M., Verhaegh, K.J., Kox, J.H.A.M., Beek, A.J. van der, Boot, C.R.L, Roelofs, P.D.D.M., Francke, A.L. Late dropout from nursing education: An interview study of nursing students' experiences and reasons. Nurse Education in Practice: 39 (2019) 17-25

Appendix B. Characteristics of the study population

\begin{tabular}{llllll}
\hline Respondent & Gender & Educational background & Age at start/age at withdrawal & Domestic situation year 3 & Educational trajectory \\
\hline 1. & f & higher secondary education (HAVO)* & $17 / 21$ & Independent & Full-time \\
2. & f & higher secondary education (HAVO) & $18 / 22$ & Independent & Full-time/combined paid work and study trajectory \\
3. & f & higher secondary education (HAVO) & $18 / 22$ & Independent & Full-time \\
4. & f & higher secondary education (VWO) & $19 / 23$ & Independent & Full-time/honours programme \\
5. & f & higher secondary education (HAVO) & $18 / 21$ & Independent & Full-time/combined paid work and study trajectory \\
6. & f & Bachelor's in Social Sciences degree & $30 / 34$ & With partner & Part-time/combined paid work and study trajectory \\
7. & m & higher secondary education (HAVO) & $18 / 22$ & With parents & Full-time \\
8. & f & higher secondary education (HAVO) & $18 / 21$ & With parents & Full-time/combined paid work and study trajectory \\
9. & f & higher secondary education (VWO) & $19 / 23$ & Independent & Full-time/honours programme \\
10. & f & higher secondary education (HAVO) & $18 / 21$ & Independent & Full-time \\
11. & f & secondary vocational training & $20 / 21$ & Independent & Full-time \\
\hline
\end{tabular}

*In the Netherlands the entrance requirements for the Bachelor's Nursing degree programme is higher secondary education (in Dutch: HAVO or VWO) or secondary vocational training.

Appendix C. Interview guide

Theme 1: Experiences in the Bachelor Nursing educational programme

How did you arrive at the decision to do a degree in nursing?

Topics:

- Expectations of nursing education/nursing profession

- Experiences from year 1 on

- Experiences theoretical programme

- Experiences clinical placements

- Role of clinical supervisor/co-workers/nursing staff and coach/fellow students

- Experienced support

- Learning environment during clinical placements/university

- Link between education and practice

- Match between training and ambition

- Expectations versus experienced reality

- Experienced physical and mental health

- Financial situation

Theme 2: Coping with training challenges

You have just sketched how your degree programme went; you have faced some challenges. Can you tell me how dealt with them?

Topics:

- Dealing with challenges (coping)

- Personal situation

- Ways to relax after clinical placements/classes

Theme 3: Received support concerning training challenges

$>$ Which people or roles could you turn to for support with the academic and practical elements of the degree programme? 
Bakker, E.J.M., Verhaegh, K.J., Kox, J.H.A.M., Beek, A.J. van der, Boot, C.R.L, Roelofs, P.D.D.M., Francke, A.L. Late dropout from nursing education: An interview study of nursing students' experiences and reasons. Nurse Education in Practice: 39 (2019) 17-25

Topics:

- Nature of the support

- Satisfaction with support

- Experience with help-seeking

Theme 4: Reasons for leaving nursing education

$>$ You unenrolled in year 3. Can you say something about the reasons why you quit the programme? Topics:

- Reasons related to theoretical part of the training (university)

- Reasons related to the clinical placements

- Reasons related to the nursing profession

- Personal reasons

- Private circumstances (family circumstances, financial situation, etc.)

Theme 5: Decision-making process regarding stopping the study program

Can you tell me how you arrived at the decision to stop?

Topics:

- Moment of considering stopping

- Persons involved

- Different steps in decision-making

Theme 6: Prevention of dropout from nursing education from the perspective of formal nursing students

$>$ What did you personally feel was lacking in your degree programme that perhaps could have prevented you from stopping?

Topics:

- Preferred changes in educational programme (at university/in clinical placements)

- Preferred support (at university/in clinical placements)

Final questions

$>$ Looking back to the period when you were studying nursing, what do you remember most?

$>$ Is there anything else you would like to share that could be important for this research?

$>$ Do you have any further questions and/or comments about the interview?

\section{References}

Andrew, S., Salamonson, Y., Weaver, R., Smith, A., O'Reilly, R., Taylor, C., 2008. Hate the course or hate to go: semester differences in first year nursing attrition. Nurse Educ.Today 28 (7), 865-872.

https://doi.org/10.1016/j.nedt.2007.12.007. 
Bakker, E.J.M., Verhaegh, K.J., Kox, J.H.A.M., Beek, A.J. van der, Boot, C.R.L, Roelofs, P.D.D.M., Francke, A.L. Late dropout from nursing education: An interview study of nursing students' experiences and reasons. Nurse Education in Practice: 39 (2019) 17-25

Association of Universities in the Netherlands, 2012. Netherlands Code of Conduct for Scientific Practice. VSNU, The Hague. https://www.vsnu.nl/files/documenten/Domeinen/Onderzoek/ The_Netherlands_Code_of_Conduct_for_Scientific_Practice_2012.pdf, Accessed date: 24 April 2019.

Bakker, E.J., Kox, J.H., Miedema, H.S., Bierma-Zeinstra, S., Runhaar, J., Boot, C.R., van der Beek, A.J., Roelofs, P.D., 2018. Physical and mental determinants of dropout and retention among nursing students: protocol of the SPRiNG cohort study. BMC Nurs. 17 (1), 27. https://doi.org/10.1186/s12912018-0296-9.

Braun, V., Clarke, V., 2006. Using thematic analysis in psychology. Qual. Res. Psychol. 3 (2), 77-101. https://doi.org/10.1016/j.profnurs.2007.06.006.

Buchan, J., Seccombe, I., 2011. A Decisive Decade. The UK Nursing Labour Market Review. Royal College of Nursing, London. https://scadmin.rcn.org.uk/professionaldevelopment/ publications/pub004170, Accessed date: 24 April 2019.

Dante, A., Valoppi, G., Saiani, L., Palese, A., 2011. Factors associated with nursing students' academic success or failure: a retrospective Italian multicenter study. Nurse Educ. Today 31 (1), 5964. https://doi.org/10.1016/j.nedt.2010.03.016.

Deary, I.J., Watson, R., Hogston, R., 2003. A longitudinal cohort study of burnout and attrition in nursing students. J. Adv. Nurs. 43 (1), 71-81. https://doi.org/10.1046/i. 13652648.2003.02674.x. Eick, S.A., Williamson, G.R., Heath, V., 2012. A systematic review of placement-related attrition in nurse education. Int. J. Nurs. Stud. 49 (10), 1299-1309. https://doi.org/10.1016/.ijnurstu.2011.12.004. Gaynor, L., Gallasch, T., Yorkston, E., Stewart, S., Bogossian, F., Fairweather, C., Foley,D., Nutter, H., Thompson, J., Stewart, L., 2007. The future nursing workforce in Australia: baseline data for a prospective study of the profile, attrition rates and graduate outcomes in a contemporary cohort of undergraduates. Aust. J. Adv. Nurs.25 (2), 11. http://www.ajan.com.au/Vol25/AJAN_25-2.pdf, Accessed date: 24August 2018.

Global Health Workforce Alliance, 2013. A Universal Truth: No Health without a Workforce: Third Global Forum on Human Resources for Health Report 2013. World Health Organization, Geneva. http://www.who.int/workforcealliance/knowledge/resources/hrhreport2013/en/, Accessed date: 24 August 2018.

Glogowska, M., Young, P., Lockyer, L., 2007. Should I go or should I stay? A study of factors influencing students' decisions on early leaving. Act. Learn. High. Educ. 8 (1),63-77. https://doi.org/10.1177/1469787407074115.

Glossop, C., 2002. Student nurse attrition: use of an exit-interview procedure to determine students' leaving reasons. Nurse Educ. Today 22 (5), 375-386. https://doi.org/10. 1054/nedt.2001.0724. Griswold, C.M., 2014. Understanding Causes of Attrition of 1st-And 2nd-Year Nursing Students. Walden University. https://scholarworks. waldenu.edu/cgi/viewcontent.cgi?referer=\&httpsredir= 1\&article $=1141 \&$ context=dissertations, Accessed date:24 April 2019.

Hamshire, C., Willgoss, T.G., Christopher, W., 2012. The placement was probably the tipping point' the narratives of recently discontinued students. Nurse Educ. Pract. 12 (4), 182-186. https://doi.org/ 10.1016/j.nepr.2011.11.004.

Harvey, V., McMurray, N., 1994. Self-efficacy: a means of identifying problems in nursing education and career progress. Int. J. Nurs. Stud. 31 (5), 471-485. https://doi.org/ 10.1016/0020-7489(94)900175 .

Harvey, V.C., McMurray, N.E., 1997. Students' perceptions of nursing: their relationship to attrition. J. Nurs. Educ. 36 (8), 383-389. https://doi.org/10.3928/0148-4834-19971001-08.

Joldersma, C., Laarman-Wierenga, M., Brink, M., 2016. Arbeid in Zorg en Welzijn 2016. Eindrapport. [Work in Care and Welfare 2016. Final report]. CAOP, Den Haag. http://www.fbz.nl/ ThemaDocumenten/Arbeidsmarktrapportage\%20azwinfo \%20(februari\%202017).pdf, Accessed date: 10 September 2018. 
Bakker, E.J.M., Verhaegh, K.J., Kox, J.H.A.M., Beek, A.J. van der, Boot, C.R.L, Roelofs, P.D.D.M., Francke, A.L. Late dropout from nursing education: An interview study of nursing students' experiences and reasons. Nurse Education in Practice: 39 (2019) 17-25

Kukkonen, P., Suhonen, R., Salminen, L., 2016. Discontinued students in nursing education-Who and why? Nurse Educ. Pract. 17, 67-73. https://doi.org/10.1016/i. nepr.2015.12.007.

Last, L., Fulbrook, P., 2003. Why do student nurses leave? Suggestions from a Delphi study. Nurse Educ. Today 23 (6), 449-458. https://doi.org/10.1016/S0260-6917(03) 00063-7.

McLaughlin, K., Moutray, M., Muldoon, O.T., 2008. The role of personality and self--efficacy in the selection and retention of successful nursing students: a longitudinal study. J. Adv. Nurs. 61 (2), 211221. https://doi.org/10.1111/j.1365-2648.2007. 04492.x.

McLaughlin, K., Muldoon, O.T., Moutray, M., 2010. Gender, gender roles and completion of nursing education: a longitudinal study. Nurse Educ. Today 30 (4), 303-307. https://doi.org/10.1016/ j.nedt.2009.08.005.

Mulholland, J., Anionwu, E.N., Atkins, R., Tappern, M., Franks, P.J., 2008. Diversity, attrition and transition into nursing. J. Adv. Nurs. 64 (1), 49-59. https://doi.org/10.1111/j.1365-2648.2008.04758.x. O'Donnell, H., 2011. Expectations and voluntary attrition in nursing students. Nurse Educ. Pract. 11 (1), 54-63. https://doi.org/10.1016/j.nepr.2010.08.002.

Pryjmachuk, S., Easton, K., Littlewood, A., 2009. Nurse education: factors associated with attrition. J. Adv. Nurs. 65 (1), 149-160. https://doi.org/10.1111/j.1365-2648.2008.04852.x.

Rankin, R.F., 2009. Emotional Intelligence: Attrition and Attainment in Nursing and Midwifery Education. University of Stirling. http://citeseerx.ist.psu.edu/viewdoc/download?doi=10.1.1.877.7451 \&rep=rep1\&type=pdf, Accessed date: 24 April 2019.

Smith, M., Lloyd, G., Lobzin, S., Bartel, C., Medlicott, K., 2015. Increasing quality and quantity of student placements in smaller rural health services: it can be done. Aust. J. Rural Health 23 (4), 243246. https://doi.org/10.1111/ajr.12165.

Ten Hoeve, Y., Castelein, S., Jansen, G., Roodbol, P., 2017. Dreams and disappointments regarding nursing: student nurses' reasons for attrition and retention. A qualitative study design. Nurse Educ. Today 54, 28-36. https://doi.org/10.1016/j.nedt.2017.04. 013. Vereniging Hogescholen, 2018. Feiten en cijfers. [Facts and figures]. http://cijfers. vereniginghogescholen.nl/QvAJAXZfc/opendoc.htm? document=4_uitval.qvw\& lang=en-US\&host=QVS\%40win-3ljdvupmkp8\&anonymous=true, Accessed date: 10 September 2018.

Willis, L., 2015. Raising the Bar. Shape of Caring: A Review of the Future Education and Training of Registered Nurses and Care Assistants. https://hee.nhs.uk/sites/default/ files/documents/2348-Shapeof-caring-review-FINAL.pdf, Accessed date: 10 September 2018.

Wilson, H.S., Levy, J., 1978. Why RN students drop out. Nurs. Outlook 26 (7), 437-441.

Wismar, M., Maier, C.B., Sagan, A., Glinos, I.A., 2018. Developments in Europe's Health workforce: addressing the conundrums. Eurohealth Syst. Policies 24 (2), 38-42. ttp://www.euro.who.int/en/aboutus/partners/observatory/publications/ eurohealth/observatory-20th-anniversary-special-issue.

Young, S., Acord, L., Schuler, S., Hansen, J.M., 2014. Addressing the community/public health nursing shortage through a multifaceted regional approach. Public Health Nurs. 31 (6), 566-573. https://doi.org/10.1111/phn.12110.

Zhang, X., Tai, D., Pforsich, H., Lin, V.W., 2017. United States registered nurse workforce report card and shortage forecast: a revisit. Am. J. Med. Qual. 33 (3), 229-236. https://doi.org/10.1177/ 1062860617738328 
Bakker, E.J.M., Verhaegh, K.J., Kox, J.H.A.M., Beek, A.J. van der, Boot, C.R.L, Roelofs, P.D.D.M., Francke, A.L. Late dropout from nursing education: An interview study of nursing students' experiences and reasons. Nurse Education in Practice: 39 (2019) 17-25

\section{Tables and figures}

Figure 1 Characteristics of the Dutch Bachelor of Nursing degree programme

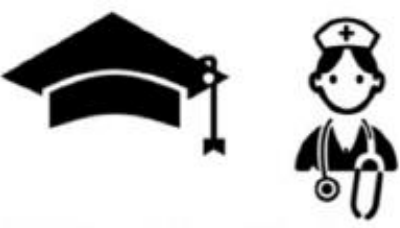

Dutch Bachelor of Nursing programme

- 17 Dutch universities of applied sciences

- $\quad$ NVAO accredited

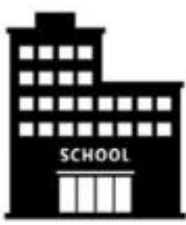

Entrance requirements

Certificate of:

- higher secondary education

- secondary vocational training

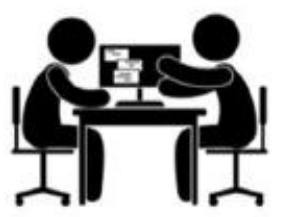

\section{Support structure}

- personal study career coach

- clinical supervisor and/or mentor

- student counsellor on demand

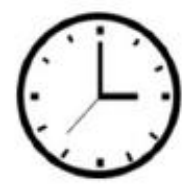

Duration of the programme

- four years

- 240 ECTS $(1 \mathrm{ECT}=28 \mathrm{hrs})$

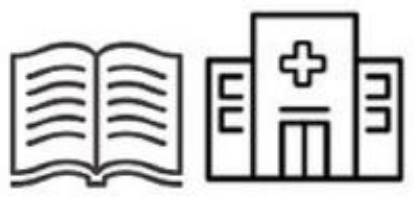

Content programme

- 1535 hrs theoretical - 2300 hrs practical

- clinical placements in various healthcare settings

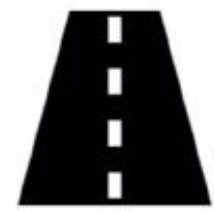

Educational trajectories

- full-time/ part-time,

- combined work-study trajectories

- honors programme 